\title{
Gingival recession behavior with immediate implant placement in the anterior maxilla with buccal dehiscence without additional augmentation-a pilot study
}

\author{
Veronika Pohl $^{1}$ (D) $\cdot$ Lukas Fürhauser $^{1} \cdot$ Robert Haas $^{1} \cdot$ Sebastian Pohl $^{2}$ \\ Received: 27 February 2019 / Accepted: 19 December 2019 /Published online: 8 January 2020 \\ (C) The Author(s) 2020
}

\begin{abstract}
Background Immediate implant placement in the presence of intact extraction alveoli has frequently been reported, while hardly any reports on immediate implant placement in missing buccal bone can be found in literature.

Objectives This pilot study evaluates esthetic outcome and soft and hard tissue level changes of immediate implant placement with immediate provisionalization in patients with partially/completely missing buccal bone without any further augmentation procedure in the maxillary anterior zone.

Material and methods Twelve patients (TG) with partially to completely missing buccal bone designated for extraction and flapless immediate implant insertion in the anterior zone of the maxilla were included. Patients randomly selected out of a larger group of patients with immediate implants with intact alveoli served as controls (CG). Immediate provisionalization was done without any further augmentation of the alveolar ridge. Marginal hard and soft tissue levels, PES, and implant success were evaluated during a 1-year observation period.

Results The defect of the buccal alveolar bone was $4.96 \mathrm{~mm}$ (min., $2.26 \mathrm{~mm}$; max., $9.68 \mathrm{~mm}$ ) and the mean mesio-distal extension $4.25 \mathrm{~mm}$ (min., $3.2 \mathrm{~mm}$; max., $5.91 \mathrm{~mm}$ ). Preoperative PES differed significantly between TG (9.68) and CG (12.25) and improved in TG postoperatively with no significant difference to CG after 1 year (TG, 10.91; CG, 11.3). The buccal soft tissue level remained almost unchanged over the observation period (TG preop, $0.86 \mathrm{~mm} \pm 0.90 \mathrm{~mm} ; 1 \mathrm{year}, 0.91 \mathrm{~mm} \pm$ $0.96 \mathrm{~mm}$; CG preop, $0.98 \mathrm{~mm} \pm 0.87 \mathrm{~mm}$; 1 year, $0.98 \mathrm{~mm} \pm 0.87 \mathrm{~mm}$ and did not show any correlation with either the mesial/ distal bone level or the initial buccal vertical defect at any point of time.

Conclusions These clinical results provide evidence that immediate implant placement without additional augmentation, but with immediate provisionalization might be a viable treatment alternative even with missing buccal plate in the esthetic maxillary zone.
\end{abstract}

Keywords Missing buccal bone $\cdot$ Flapless $\cdot$ Immediate implants $\cdot$ Immediate loading $\cdot$ No augmentation

Principal findings Both treatment approaches, immediate implantation and immediate provisionalization in intact extraction sockets as well as in alveoli with buccally missing bone rendered similar outcomes with regard to PES, height of the buccal gingival margin, and the peri-implant bone level after 1 year.

Veronika Pohl

pohl@implantatakademie.at

1 Academy for Oral Implantology, Lazarettgasse 19/DG, 1090 Vienna, Austria

2 Department of Oral and Maxillofacial Surgery, Medical University Vienna, Vienna, Austria

\section{Introduction}

Immediate implant placement in the anterior maxillary zone is a potential approach for meeting patients' requests and desires regarding treatment time, treatment costs, and esthetic outcome, especially for cases with single tooth restorations. Immediate placement of an implant in the extraction alveolus is to counteract the extraction-related bone loss: As early as two weeks following tooth extraction, the complete segment of the bundle bone of the buccal plate will be fully absorbed [1] with concomitant resorption of the bony alveolar margins. After 3 months, the loss of bone level will be $0.2 \mathrm{~mm}$ lingually and about $0.6 \mathrm{~mm}$ in buccal position $[1,2]$. Thus, the first year after tooth extraction will be associated with a horizontal loss 
of the alveolar process being most pronounced in the area of the buccal lamella [3].

Considering the clinical results of immediate implant placement with regard to the preservation of the buccal lamella, an average loss of vestibular soft tissue height ranging between $0.7 \pm 0.57$ and $1,0 \pm 0.9 \mathrm{~mm}$ can be observed [4].

It is especially with immediate implant placement that different treatment approaches have been described, predominantly being based on personal experience and scientific evidence from clinical studies. The following factors may be considered as appropriately supported by clinical evidence:

Mucoperiostal elevation in the course of immediate implant placement may result in major bone loss, especially on the buccal lamella $[5,6]$ with the alveolar bone loss increasing with the frequency of bone denudation [7].

The implant should be inserted into the palatal alveolar wall without contacting the buccal bone lamella [8]. In this respect, superior esthetic results have been described with a gap of $>2.5 \mathrm{~mm}$ between implant and anterior alveolar margin [9]. Some authors request insertion of bone replacement material or autologous tissue as with a distance of $>2 \mathrm{~mm}$ between buccal lamella and implant $[10,11]$. However, no comparative assessments supporting this expert opinion have yet been reported according to the knowledge of the authors.

A recently published study was able to show that placing a deproteinized bovine bone graft with $10 \%$ collagen significantly reduced the horizontal bone resorptive changes occurring in the buccal bone after the immediate implantation in fresh extraction sockets [12] while no such effect could be demonstrated in previous animal studies $[6,13]$.

A literature review revealed that - apart from the bony support of the buccal gingiva-immediate prosthetic restoration of the implant with a provisional crown and a flapless approach will be of critical importance [14].

Regardless of a potential filling of the defect, this type of implant therapy will represent a meaningful complementation of treatment for preserving the buccal lamella and the surrounding soft tissue, especially for the esthetically demanding anterior maxilla $[15,16]$.

In all these studies, presence of the buccal bone lamella had been a principal prerequisite. Thus, it is also seen as a basic requirement that the buccal bone lamella must be preserved for allowing immediate implant placement. According to current scientific opinion, loss of the buccal lamella constitutes a contraindication for immediate implant placement, and a socket preservation technique should be used instead in such cases [17].

A single exploratory cohort study in an overall 16 patients evaluated the performance of a flapless surgical approach for immediate implant placement, simultaneous alveolar ridge augmentation, and immediate provisionalization in patients with complete loss of the facial bony lamella. On average, interproximal marginal bone levels stabilized at 1.0 to $1.3 \mathrm{~mm}$ above the first thread and marginal esthetics, as assessed by the pink esthetic score (PES), was by large preserved [11]. Currently, no other publications discussing the changes of soft and hard tissue in the presence of buccal dehiscence are available.

Thus, the purpose of this pilot study was to report the results for immediate flapless placement of implants with immediate provisionalization in the anterior maxilla with partially or completely missing buccal bone and without further socket grafting.

\section{Material and methods}

The following criteria/requirements had to be fulfilled for inclusion in this pilot study in a consecutive patient population:

- Presence of a single tooth to be extracted in the esthetic zone of the maxilla [13-23].

- Presence of a partial defect of the buccal bony alveolar lamella (at least $25 \%$ of the length of the corresponding tooth) up to a completely missing buccal plate as shown in a preoperative cone beam computed tomography (CBCT). Patients with exclusive fenestration defects-i.e., with at least partially preserved crestal bridge of the buccal alveolar wall-were excluded.

- Acceptance of the prevailing esthetic situation by the patient prior to starting treatment and no wish for any changes.

The test group (TG) was compared with a randomly selected patient cohort of identical size showing no defects of the bony vestibular lamella but requiring restoration using single tooth implants (control group/CG).

Thus, the inclusion criteria for the $\mathrm{CG}$ had to be identical to those of the TG, except the presence of an intact buccal bony alveolar lamella.

Randomization was done with the function sample in $\mathrm{R}$ [18] out of all patients fulfilling the inclusion criteria for CG retrospectively $(n=415)$. (Fig. 1$)$.

The same therapeutic procedure was used for both groups. All implant placements were done by the same surgeon. Preoperatively, the patients were given a single oral antibiotic dose of $2 \mathrm{~g}$ amoxicillin/clavulanic acid (Augmentin ${ }^{\circledR}$, GlaxoSmithKline Pharma GmbH, Vienna). Following cautious and utterly careful tooth extraction, the alveola was carefully excochleated without elevating the flap and under careful preservation of the papilla. A dental implant (NobelReplace Tapered, Nobel ${ }^{\circledR}$ Biocare, Kloten, Switzerland) was inserted into the apical or palatal portion of the alveolar process according to the drilling protocol for achieving a torque of at least $>35 \mathrm{Ncm}$. The buccal crestal margin of the implant had to be at least $3 \mathrm{~mm}$ below the deepest indention of the gingival margin and $3 \mathrm{~mm}$ palatally of the same [8]. The implant had 


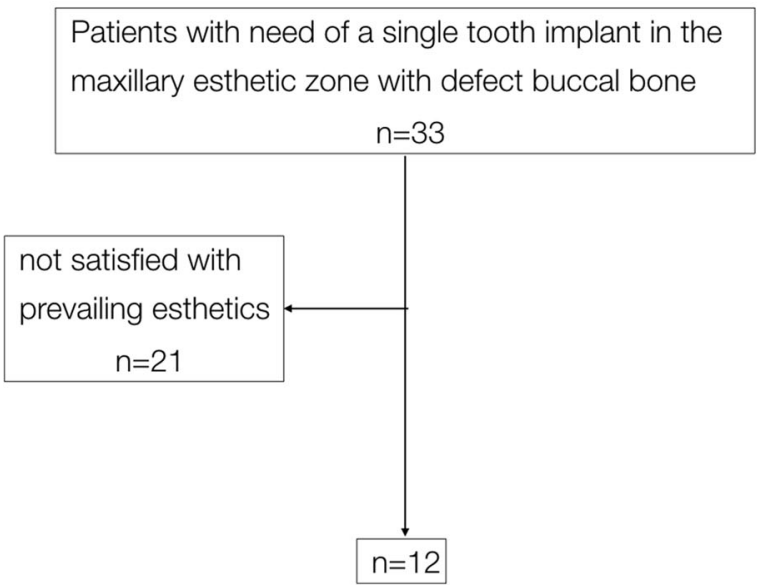

CONTROL

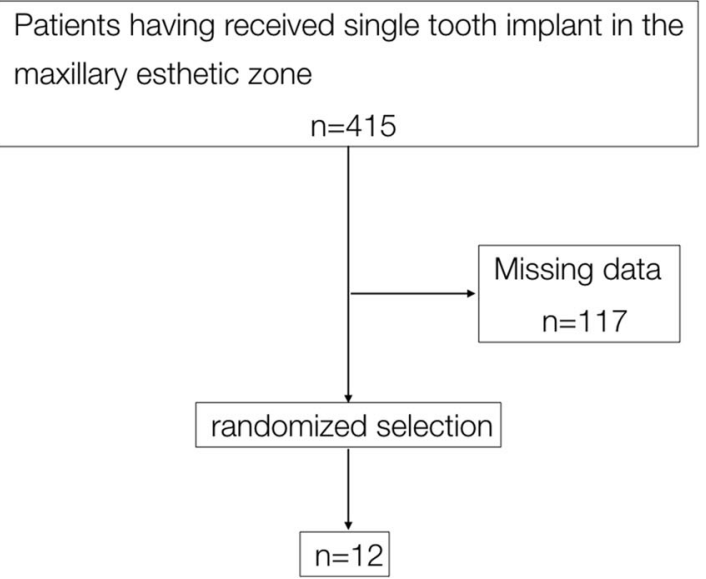

Fig 1 Flow chart of the study design

no direct contact with the buccal portions of the facial bone or soft tissue. Thus, the orientation of the implant position was soft-tissue- but not hard-tissue-related. As already described in a different context, provisional rehabilitation in both groups was done using a copy abutment [19] initially in synthetic material exactly imitating the gingival emergence profile of the original tooth. Special care was taken not to give any pressure due to the abutment design to the soft tissues as seen by a change of the color from pink to white as this might influence the soft tissue margin [20]. On the 3rd to 5th postoperative day, this abutment was replaced by a copy of zirconium oxide and fixed with a torque of $20 \mathrm{Ncm}$. Both abutments were provided with the same provisional crown having no interproximal contact with neighboring teeth or eccentric contact with opposing teeth. The patients were permitted to continue their routine oral hygiene still on the day of surgery using a toothbrush with soft bristles. After a healing phase of 3-4 months, the abutment screws were fixed using a torque of $25 \mathrm{Ncm}$, and the provisional crowns were replaced by ceramic crowns (Initial Zr-FS®' GC, Leuven, Belgium) by the use of conventional impression technique (Impregum ${ }^{\circledR}, 3 \mathrm{M}$, St. Paul/Minnesota, USA). In case of a possible visibility of abutment margins due to mucosal retraction, the abutment was ground using diamond drills (Komet ${ }^{\circledR}$, Lemgo, Germany) taking special attention not to touch the soft tissue. The definitive abutments were neither removed at that time nor at any later point of time.

The buccal defect was determined by sagittal reconstruction according to the longitudinal axis of the implant in the postoperative CBCT scan (Classic iCAT, Imaging Sciences International, Hatfield, PA, USA, imaging mode 0.25 voxel High Resolution, Carestream ${ }^{\circledR}$, Atlanta, USA). The distance between two verticals on the implant axis from the most crestal bone margin to the upper implant edge yielded the vertical defect of the buccal lamella. (Fig. 2).
In addition, the maximum size of the defect was evaluated at the transverse section and vertical to the implant axis (Fig. 3).

For assessing the mesial and distal bone level, intraoral radiographs (Sidexis ${ }^{\circledR}$, Sirona, Bensheim, Germany) were taken on the day of surgery and 4, 6, and 12 months postoperatively. The distance between the upper edge of the implant and the first contact of the bone with the implant body was determined both mesially and distally following calibration with the known implant length. Negative values represented a bone defect, while positive ones a bone level exceeding the implant margin.

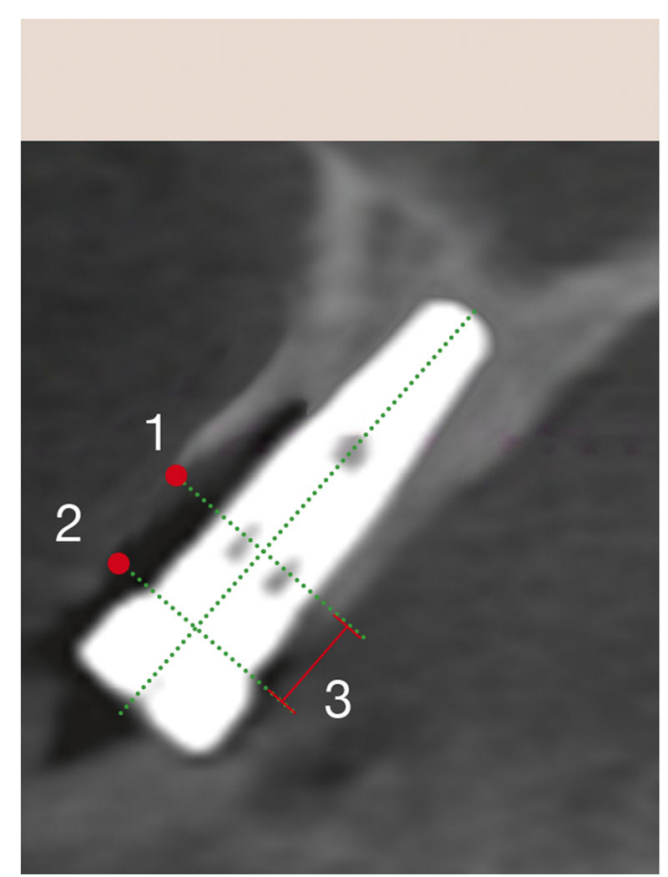

Fig 2 Measurement of the defect of the buccal lamella. (1) Vertical to implant axis at bone level on buccal side. (2) Vertical to implant axis at level of upper implant edge. (3) Length of the vertical bone defect 


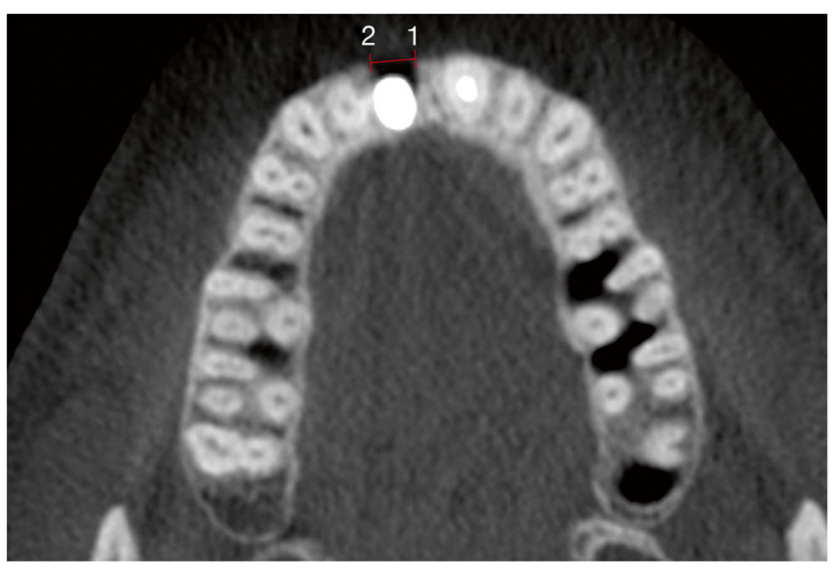

Fig. 3 Measurement of the defect in mesio-distal direction $(=4.02 \mathrm{~mm})$. Location 1 marks the start of the defect mesial to the implant in region 11. Location 2 represents the endpoint of measurement distal to the implant 11

For assessing the buccal soft tissue profile, intraoral photographs (Canon EOS-1D X, Canon EF $100 \mathrm{~mm}$ f/2.8 L Macro IS USM, Macro Ring Lite MR-14EX) were taken preoperatively and postoperatively after 1 year. The images each comprised the region to be assessed as well as the contralateral tooth (Fig. 4).

The parameters assessed included the pink esthetic score (PES) [21]: the mesial and distal papilla, the level, contour, color, structure and texture of the soft tissue, and the alveolar ridge of both the test and the control tooth. All measurements of the PES were taken in blinded manner by two students in training for dentist, an experienced implantologist and an experienced implant prosthodontist.

In addition, a straight line was placed through the most apical point of the gingiva of the neighboring teeth of the implant, and a vertical to this line to the most apical point of the mucosa of the implant crown was determined. Measurements were done in $\mathrm{mm}$ based on the actual crown length of one of the neighboring teeth. The preoperative setting on the baseline photograph was taken as zero point of the recession measurement. Positive values represented a gain, negative values, a loss in marginal mucosa (recession). For documenting the course of the mucosal recession, photographs were taken immediately, postoperatively, and at week 1 and months $1,4,6$, and 12 .

\section{Statistical evaluation}

The results were evaluated using descriptive statistical analysis. Potential differences between the study cohorts were evaluated using the Mann-Whitney $U$ test and the Wilcoxon signed rank test; potential correlations were studied using the Wilcoxon rank sum test. A $p$ level of $<0.05$ was taken as significance level. The primary outcome was the difference of soft tissue esthetics after 1 year in single-tooth immediate implants and immediate provisionalization between partially/ completely missing buccal bone and sites with intact buccal bone. H0- there was no difference in PES, H1- both groups differ.

Secondary outcome was the difference in marginal bone level between those two groups after 1 year of function. $\mathrm{H} 0$ groups do not differ in terms of bone level, H1- groups differ.

The control group was selected by the random sample. [22]

Since there did not exist any comparable study to calculate a power analysis before this pilot study, a post-hoc power analysis (means; Wilcoxon-Mann-Whitney) [23] was performed for PES and for the bone level values.

The study had been reviewed and approved by the Ethics Committee of the Medical University Vienna (No. 497/2010).
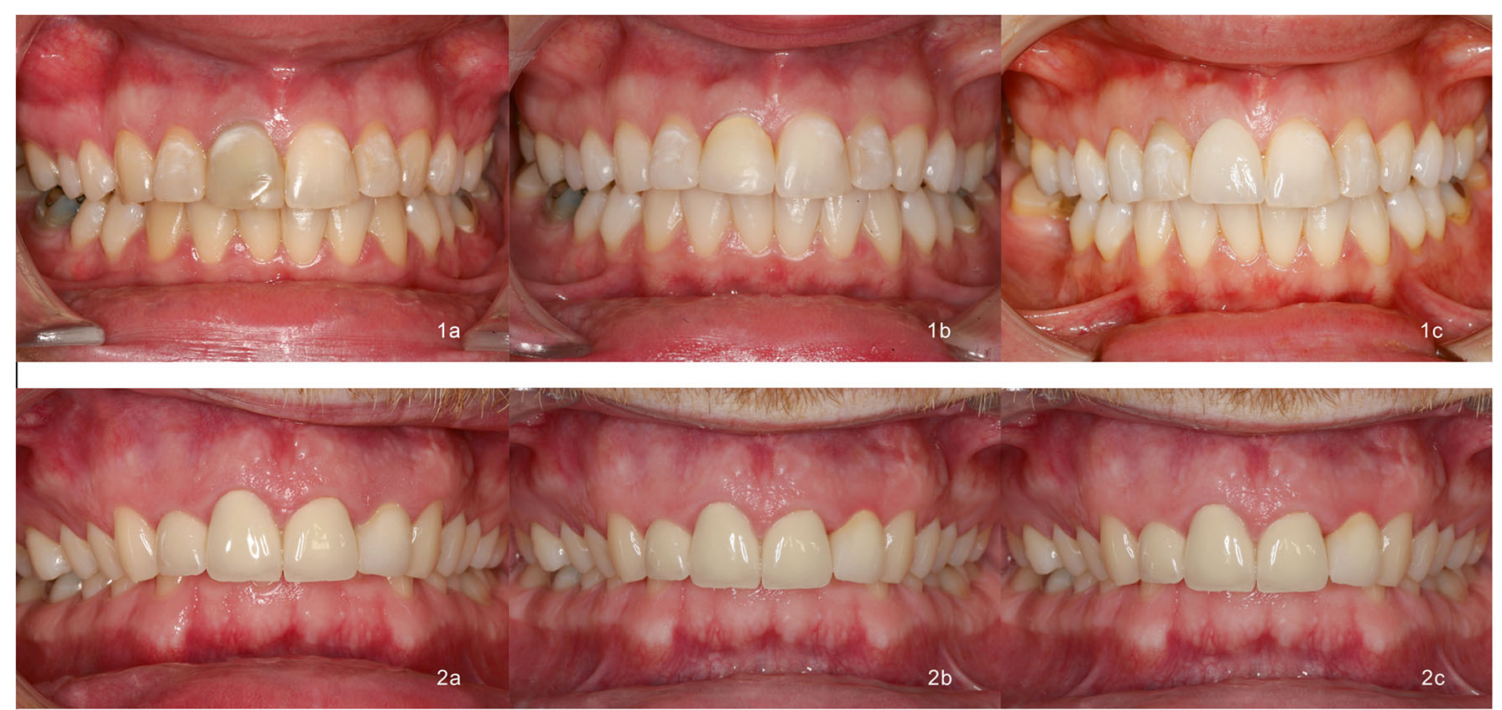

Fig. 4 Pictures of the clinical course for two patient cases. TG (1) upper row: right central incisor: preoperative (1a), postoperative (1b), and 1-year postimplantation (1c) and CG (2) bottom row: left lateral incisor preoperative (2a), postoperative (2b), 1-year post-implantation (2c) 
All the statistical calculations were done by a statistician who was not involved in any further investigations of the present study.

\section{Results}

An overall 11 males (average age 50.4 years) and 13 females (average age 42.5 years) were enrolled in the study. The study group TG comprised 4 males and 8 females. The immediate implants involved 2 implants in the location of the canine (2 TG, $0 \mathrm{CG}$ ), 7 cases in the location of the lateral incisor (3TG, $4 \mathrm{CG}$ ), and 15 cases in the location of the central incisor ( $7 \mathrm{TG}, 8 \mathrm{CG}$ ). The causes of the tooth loss were root fractures (TG 7, CG 3), dental trauma (TG 1; CG 0 ), chronic apical periodontitis (TG 2; CG 1), crown fracture (TG 0; CG 6), external root resorption (TG 0; CG 1), and internal granuloma (TG 0; CG 1).

Conical implants with a diameter of $4.3 \mathrm{~mm}$ and a length of $13 \mathrm{~mm}(n=11)$ or $16 \mathrm{~mm}(n=14)$ were used. The postoperative course was free of complications, and all implants remained under function during the complete follow-up period. Before taking the impression for the final crown, minimal reshaping of the buccal margin of the ceramic copy abutment (less than $0.2 \mathrm{~mm}$ ) had to be performed in every patient regardless of the group. Figure 3 shows two clinical examples for $\mathrm{TG}$ and $\mathrm{CG}$.

At the time of implant placement, the average vertical defect of the buccal lamella in the TG was $4.96 \mathrm{~mm}$ (min., $2.26 \mathrm{~mm}$; max., $9.68 \mathrm{~mm}$ ) and the average mesio-distal extension was $4.25 \mathrm{~mm}$ (min., $3.2 \mathrm{~mm}$, max., $5.91 \mathrm{~mm}$ ).

The average postoperative bone level for the TG was 2.60 $\pm 2.67 \mathrm{~mm}$ (mesial, $2.46 \pm 3.45 \mathrm{~mm}$; distal, $2.97 \pm 2.40 \mathrm{~mm}$ ) and for the $\mathrm{CG}$ was $1.72 \pm 1.09 \mathrm{~mm}$ (mesial, $1.55 \pm 1.43$. $\mathrm{mm}$; distal, $1.88 \pm 0.96 \mathrm{~mm})(p=0.51)$ and the bone level at 12 months was $1.58 \pm 2.33 \mathrm{~mm}$ (mesial, $1.42 \pm 2.32 \mathrm{~mm}$; distal, $1.75 \pm 2.34 \mathrm{~mm}$ ) for TG and $1.42 \pm 0.71 \mathrm{~mm}$ (mesial, $1.24 \pm 0.76 \mathrm{~mm}$; distal, $1.59 \pm 0.82 \mathrm{~mm})$ for $\mathrm{CG}(p=0.41)$ (Fig. 5). Although the effect of time on mesial and distal bone level was obvious for both groups together $(p=0.01)$, this effect could no longer be demonstrated upon separate evaluation of $\mathrm{TG}$ and $\mathrm{CG}(p>0.05)$. The average preoperative PES score was $9.68 \pm 2.52$ in the TG and 12 . $25 \pm 1.29$ in the CG $(p=0.005)$ and the scores after 1 year were $10.91 \pm 2.6(\mathrm{TG})$ and $11.3 \pm 2.31(\mathrm{CG})(p=0.621)$. The difference between the preoperative PES scores and those of the postoperative evaluation was significant for the TG ( $p 0$. 028), but not for the CG $(p=0.271)$ (Tab. 1). Overall, the total PES scores improved in 12 patients (TG, 8; CG, 3) from the preoperative setting to 12 months postoperative, remained unchanged in 6 patients (TG, 3; CG, 3) and deteriorated in 6 patients (TG, $1 ; \mathrm{CG}, 5)$. The changes of the individual parameters of the PES at year 1 postoperative can be seen in Table 1. A post hoc two-sample power calculation of PES revealed a power of $0.89909(\alpha=0.05)$. The post hoc power calculation for bone level gave a power of 0 . 16665 .

The average preoperative height of the gingival margin was $-0.86 \mathrm{~mm} \pm 0.9 \mathrm{~mm}$ in the $\mathrm{TG}$ and $0.98 \mathrm{~mm} \pm 0.87 \mathrm{~mm}$ in the $\mathrm{CG}$; the height immediately postoperative was $-0.56 \mathrm{~mm} \pm$ $0.45 \mathrm{~mm}(\mathrm{TG})$ and $-0.40 \mathrm{~mm} \pm 0.39 \mathrm{~mm}(\mathrm{CG})$, and after 1 year $-0.91 \mathrm{~mm} \pm 0.96 \mathrm{~mm}(\mathrm{TG})$ and $-0.98 \mathrm{~mm} \pm$ $0.87 \mathrm{~mm}$ (CG), respectively (Fig. 6).

The change of the gingival margin showed no significant difference in either of the two groups within1 year $(p>0.05)$.

At no point of time, a significant correlation between the measurement of the mucosal recession and the vertical and/or mesio-distal bone defect could be seen (Table 2).

\section{Discussion}

The present study evaluates the clinical results at a time of 1year-post immediate implantation and immediate provisionalization of single-tooth implants in the esthetic zone of the maxilla with partially or completely missing buccal lamella without any additional augmentation measures.

Acceptance of the preoperative situation with regard to esthetic parameters (PES) was a prerequisite for study enrollment of patients. The key factors described by some of the authors, such as patient's smile line/lip line, gingival phenotype, as well as acute or chronic inflammatory processes in the implantation area [24] were neither inclusion nor exclusion criteria for this study. In contrast to the traceability of the PES [25], it is especially the gingiva type that is more controversially discussed with regard to its assessment and also its reproducibility [26].

For avoiding a potential impact of surgery-related factors on measurement results, all surgical interventions were performed by the same experienced implantologist who was not involved in any further evaluation of the results.

In addition and for avoiding any traumatization of the soft or hard tissue by elevation of the soft tissue with a potential impact on the results [27], the surgical intervention was performed as a flapless procedure, and the bone defects were evaluated in a three-dimensional postoperative CBCT. The upper edge of the implant body was taken as reference point. As positioning of the implants itself was determined by the mucosal margin ( $3 \mathrm{~mm}$ below the mucosal margin) and thus was located below the margin of a potential buccal lamella, it can be assumed that - upon open defect measurementactually larger vertical defects were present than those measured as median with $4.96 \mathrm{~mm}$ (min. $2.96 \mathrm{~mm}$, max. $9.68 \mathrm{~mm})$.

Moreover, the present study used immediate provisionalization for all implants in order to minimize 
Fig. 5 Bone level test group (TG), control group (CG), postoperative and at months 4,6 , and $12 ; 0=$ bone level at level of upper implant edge

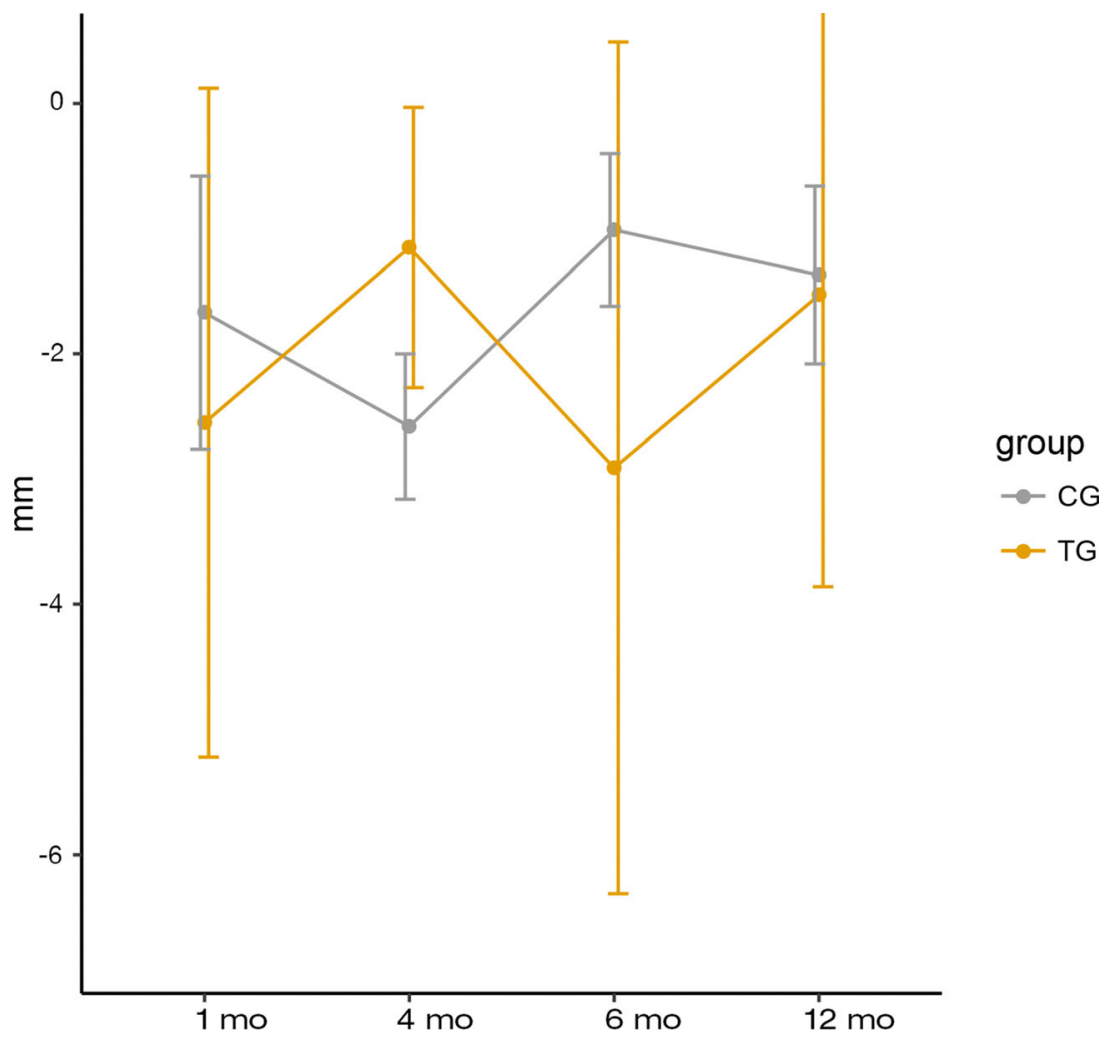

traumatization since it could be shown that every single operative intervention around implants had a significant new deteriorating influence on both peri-implant soft and hard tissue $[7,27]$ The PES was used for measuring the esthetic results in this study. The TG showed a significantly worse average PES at baseline (9.68) as compared to the CG (12.25). However, this difference could no longer be demonstrated statistically after 1 year $(\mathrm{TG}, 10.91 \pm 2.6 ; \mathrm{CG}, 11.3 \pm 2.3)$. This result was due to the significant improvement of the PES in the TG and a worse assessment in the $\mathrm{CG}$, though not being statistically significant. Based on a very good preoperative average assessment, 5 patients in the CG, but only one patient in the TG, showed a worse PES score after 1 year, while 8 patients in the TG, but only 3 patients in the CG showed an improved score. This improvement in the TG was primarily due to the significantly better assessment for those parameters of the PES being related to alveolar ridge, soft tissue structure, and soft tissue color. With regard to the parameters alveolar ridge and soft tissue contour, an alignment between the two groups after 1 year was seen due to the improved rating in the TG with a concurrent poorer rating in the CG. Obviously, the buccal bone lamella present showed postoperative catabolic remodeling resulting in a consequent volume loss of the alveolar ridge and an associated loss of soft tissue contour. [12] In obvious contrast, the esthetic aspect of the alveolar ridge in the TG remained constant during the first postoperative year as compared to the preoperative rating or the patients experienced an improvement of soft tissue contour, possibly due to a postoperative decrease of preoperative signs of inflammation. Similar results have been reported for other investigations of immediate implants without buccal defects [28]. A significant improvement in PES in the context of immediate implant placement has also been reported with simultaneous flapless augmentation with autogenous bone and connective tissue graft [29].

Other studies of immediate implant placement with preserved buccal lamella have reported a recession of the marginal mucosa of an average $0.5 \mathrm{~mm}$ [30]. In this study, the recession after 1 year was $-0.91 \mathrm{~mm} \pm 0.96 \mathrm{~mm}(\mathrm{TG})$ and $0.98 \mathrm{~mm} \pm 0.87 \mathrm{~mm}(\mathrm{CG})$, respectively. Thus, the procedure with immediate implant placement and immediate restoration described served to largely avoid the loss of the height of the buccal mucosa. The rather palatal implant position also appeared to have a particular impact: implants placed in excessively buccal position show a tendency of recession partly being as much as three times as high [30]. Similarly, the partially to completely missing buccal lamella obviously showed no impact on the mean height of the buccal soft tissue, even though differences in absolute gingiva height could be measured in individual cases. For the measurement of the mesial and distal bone level, it must be considered that with immediate implant placement, this level will not be at the height of the upper implant edge as with a late implant placement, but below (TG, $2.60 \pm 2.67 \mathrm{~mm}$; CG, $1.72 \pm 1.09 \mathrm{~mm}$ ). From this deep postoperative level, there will be a gradual shift towards the upper implant edge within the period of 1 year. The reason 
Table 1 Mean values and standard deviations (SD) of the individual parameters of the Pink Esthetic Score (PES) for test group (TG) and control group (CG) preoperative and at postoperative year 1 with the $p$ values related to the respective parameters of the group and the follow-up period

\begin{tabular}{|c|c|c|c|c|c|c|c|c|c|c|}
\hline \multirow{3}{*}{ Parameter } & \multicolumn{5}{|c|}{ Preoperative } & \multicolumn{5}{|c|}{ Year 1 postoperative } \\
\hline & TG & & $\mathrm{CG}$ & & $\mathrm{p}$ & TG & & CG & & $p$ \\
\hline & Mean & SD & Mean & SD & & Mean & $\mathrm{SD}$ & Mean & SD & \\
\hline Mesial papilla & 1.89 & 0.30 & 1.82 & 0.33 & 0.571 & 1.77 & 0.36 & 1.62 & 0.40 & 0.243 \\
\hline Distal papilla & 1.61 & 0.36 & 1.70 & 0.39 & 0.482 & 1.68 & 0.40 & 1.65 & 0.38 & 0.853 \\
\hline Soft tissue level & 1.59 & 0.64 & 1.88 & 0.13 & 0.589 & 1.36 & 0.79 & 1.48 & 0.51 & 0.913 \\
\hline Soft tissue contour & 1.30 & 0.55 & 1.73 & 0.28 & 0.030 & 1.50 & 0.64 & 1.65 & 0.41 & 0.634 \\
\hline Alveolar ridge & 1.55 & 0.44 & 1.88 & 0.18 & 0.045 & 1.52 & 0.51 & 1.65 & 0.47 & 0.635 \\
\hline Soft tissue texture & 0.95 & 0.58 & 1.62 & 0.29 & 0.009 & 1.64 & 0.44 & 1.62 & 0.46 & 1 \\
\hline Soft tissue color & 0.80 & 0.47 & 1.62 & 0.38 & 0.001 & 1.43 & 0.43 & 1.62 & 0.44 & 0.280 \\
\hline
\end{tabular}

why in both groups the distal bone level was lower than the mesial level still remains to be elucidated.

Thus, similar values could be found after 1 year as reported by other authors with both immediate implants [31] and delayed implants [32]. They are, however, somewhat higher than those reported in a recently published study of immediate and early loading of flapless placed single implants in healed sites
[33]. Possible differences may be due to the fact that in this study, a flapless procedure with immediate implant placement was used, and the depth alignment of the implants upon placement was soft-tissue-related and not determined by the hard tissue level.

In the present study, a significant impact of time on the bone level could be measured when assessing both groups
Fig. 6 Median, 1st, and 3rd quartile, min., and max. of the mucosal margin in $\mathrm{mm}$ in the $\mathrm{TG}$ and the $\mathrm{CG}$ at the various time points of measurement and in relation to the contralateral tooth. Positive values represent a course of the mucosa margin closer to the crown, negative ones a course being closer to the implant (recession)
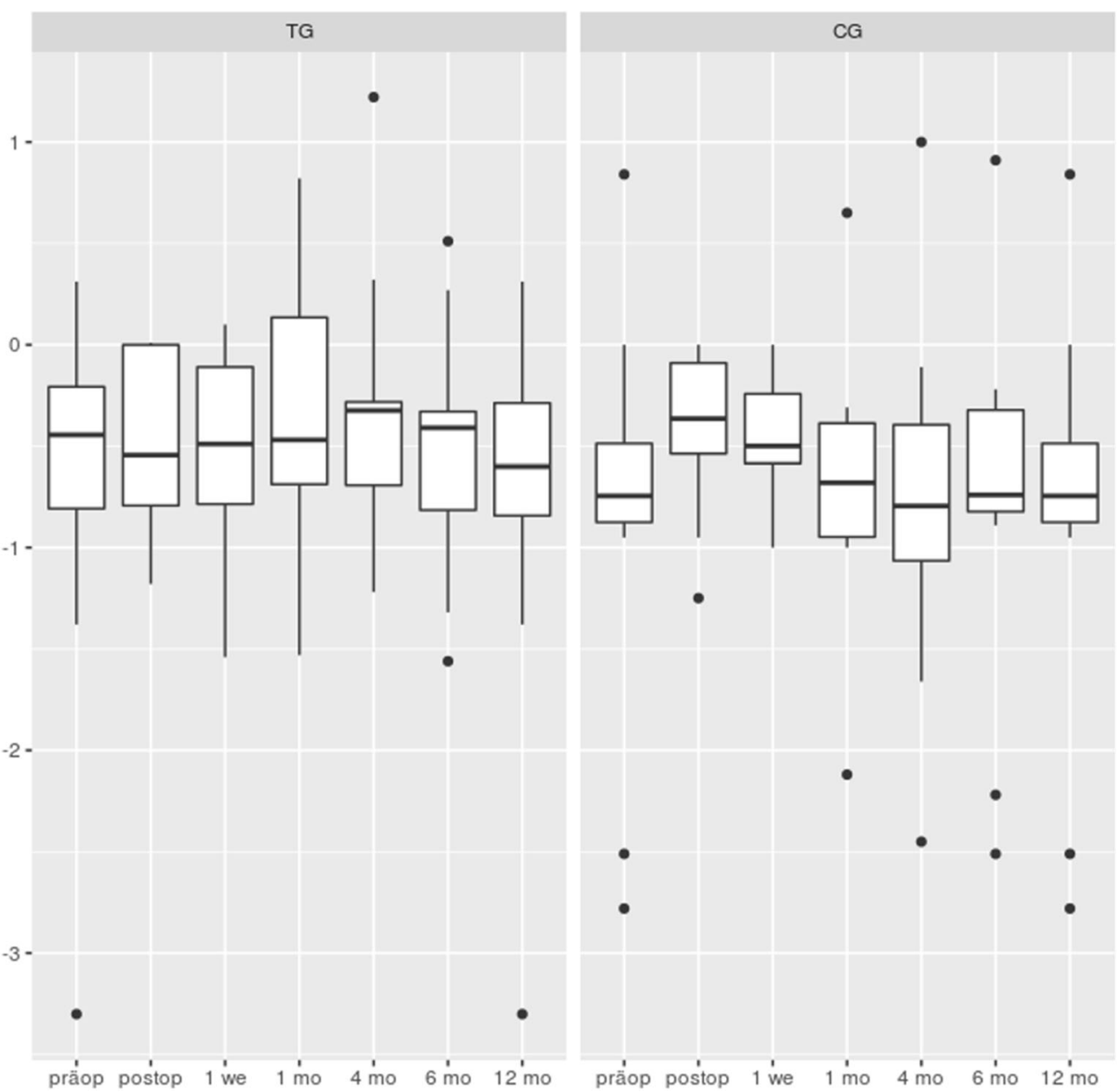
Table 2 Correlation coefficient and $p$ values of the measured mucosal recession with the mesio-distal defect at the various time points in the TG

\begin{tabular}{llllll}
\hline & \multicolumn{2}{l}{ Vertical defect (TG) } & & \multicolumn{2}{c}{ Mesio-distal defect (TG) } \\
\cline { 2 - 3 } & Correlation coefficient & $p$ value (two-sided) & & Correlation coefficient & $p$ value (two-sided) \\
\hline Postoperative & 0.429 & 0.337 & 0.270 & 0.558 \\
1 week & 0.000 & 1.000 & 0.286 & 0.456 \\
1 month & -0.191 & 0.573 & 0.210 & 0.535 \\
4 months & 0.004 & 0.991 & 0.109 & 0.780 \\
6 months & 0.107 & 0.769 & -0.079 & 0.828 \\
12 months & -0.167 & 0.667 & -0.126 & 0.748 \\
\hline
\end{tabular}

together, while this effect could no longer be statistically demonstrated when assessing bone levels separately in TG and CG. It must be assumed that this will be the case with a larger number of patients. As a matter of fact, no significant difference between TG and CG could be measured: a partially or completely missing buccal lamella obviously had no impact on either the mesial and distal bone level post-implantation or on the regenerative potency of this site during a follow-up of up to 1 year. Since the post hoc power regarding the bone level was weak (16.7\%), a final conclusion about the influence of missing buccal bone on the mesial and distal bone level cannot be drawn from this pilot study. Further studies with larger patient cohorts have to prove these results. The larger standard deviation of the bone level in the TG $(2.33 \mathrm{~mm})$ versus the $\mathrm{CG}$ $(0.71 \mathrm{~mm})$ observed in this study may possibly be due to the two alveoli of the upper canine additionally used in the TG which were not recorded in the CG. Nevertheless, the TG showed a similar mean bone level $(1.58 \mathrm{~mm})$ versus the CG $(1.42 \mathrm{~mm})$ after 1 year.

As an additional result, the present study also showed that no correlation of the height of the mucosal margin with the dimensions of the original defect of the buccal lamella or with the mesio-distal bone level at the respective assessment time points could be determined. The presence of a buccal soft tissue maintained at the normal height does not provide any evidence of an adequate preservation of the underlying bone structure. A virtually identical mucosal height in both TG and CG suggests that the buccal soft tissue has remained stable for up to 1 year even without bone support. It remains to be investigated whether this was also associated with a regeneration of the buccal bone. According to the authors "Knowledge no such evidence has yet been reported in literature." It has to be pointed out, that the observation period of this pilot study is rather short, and that a possible deterioration of PES may occur thereafter though there is evidence, that PES remains stable between 1 and 2 years [34] and up to 10 years [35] after implantation in the esthetic zone of the anterior maxilla. Further studies in a larger patient population and with prolonged follow-up periods will be required for providing final answers to this question.
Overall, the results for the TG were comparable to other results with immediate implants having been inserted under favorable bone conditions [36-38].

Hence, the results of this pilot study show that with a partial or complete loss of the buccal lamella, immediate implant placement without any additional augmentation, but with immediate provisionalization represents a potential treatment option for replacing non-preservable teeth in the esthetic zone of the maxilla.

Nevertheless, it must be stated that the present study is a pilot study. Our findings need to be confirmed in a study with larger cohorts with a bigger power. Furthermore, the results with missing buccal bone without augmentation have to be compared with the results of additional buccal augmentation together with immediate implantation and immediate provisionalization in a prospective randomized trial. However, acceptance of the preoperative esthetic setting by the patient will be a prerequisite for such an approach.

Authors' contribution Veronika Pohl- drafting article, data collection Lukas Fürhauser- critical revision of article

Robert Haas- data analysis/interpretation/statistics

Sebastian Pohl- concept/design of study

Funding Information Open access funding provided by Medical University of Vienna.

\section{Compliance with ethical standards}

Conflict of interest The authors declare that they have no conflicts of interest.

Ethical approval All procedures performed in studies involving human participants were in accordance with the ethical standards of the institutional and/or national research committee and with the 1964 Helsinki declaration and its later amendments or comparable ethical standards.

Informed consent For this type of study, formal consent is not required.

Open Access This article is licensed under a Creative Commons Attribution 4.0 International License, which permits use, sharing, adaptation, distribution and reproduction in any medium or format, as long as you give appropriate credit to the original author(s) and the source, 
provide a link to the Creative Commons licence, and indicate if changes were made. The images or other third party material in this article are included in the article's Creative Commons licence, unless indicated otherwise in a credit line to the material. If material is not included in the article's Creative Commons licence and your intended use is not permitted by statutory regulation or exceeds the permitted use, you will need to obtain permission directly from the copyright holder. To view a copy of this licence, visit http://creativecommons.org/licenses/by/4.0/.

\section{References}

1. Araujo MG, Lindhe J (2005) Dimensional ridge alterations following tooth extraction. An experimental study in the dog. J Clin Periodontol 32(2):212-218

2. Cardaropoli G, Araujo M, Lindhe J (2003) Dynamics of bone tissue formation in tooth extraction sites. An experimental study in dogs. J Clin Periodontol 30(9):809-818

3. Botticelli D, Persson LG, Lindhe J, Berglundh T (2006) Bone tissue formation adjacent to implants placed in fresh extraction sockets: an experimental study in dogs. Clin Oral Implants Res 17(4):351-358

4. Evans CD, Chen ST (2008) Esthetic outcomes of immediate implant placements. Clin Oral Implants Res 19(1):73-80

5. Cannizzaro G, Felice P, Leone M, Checchi V, Esposito M (2011) Flapless versus open flap implant surgery in partially edentulous patients subjected to immediate loading: 1-year results from a split-mouth randomised controlled trial. Eur J Oral Implantol 4(3):177-188

6. Favero G, Lang NP, Romanelli P, Pantani F, Caneva M, Botticelli D (2015) A digital evaluation of alveolar ridge preservation at implants placed immediately into extraction sockets: an experimental study in the dog. Clin Oral Implants Res 26(1):102-108

7. Cosyn J, Cleymaet R, De Bruyn H (2016) Predictors of alveolar process remodeling following ridge preservation in high-risk patients. Clin Implant Dent Relat Res 18(2):226-233

8. Furhauser R, Mailath-Pokorny G, Haas R, Busenlechner D, Watzek G, Pommer B (2015) Esthetics of flapless single-tooth implants in the anterior maxilla using guided surgery: association of threedimensional accuracy and Pink Esthetic Score. Clin Implant Dent Relat Res 17(Suppl 2):e427-e433

9. Pluemsakunthai W, Le B, Kasugai S (2015) Effect of buccal gap distance on alveolar ridge alteration after immediate implant placement: a microcomputed tomographic and morphometric analysis in dogs. Implant Dent 24(1):70-76

10. Grunder U, Gracis S, Capelli M (2005) Influence of the 3-D boneto-implant relationship on esthetics. Int J Periodontics Restorative Dent 25(2):113-119

11. Noelken R, Kunkel M, Wagner W (2011) Immediate implant placement and provisionalization after long-axis root fracture and complete loss of the facial bony lamella. Int J Periodontics Restorative Dent 31(2):175-183

12. Sanz M, Lindhe J, Alcaraz J, Sanz-Sanchez I, Cecchinato D (2017) The effect of placing a bone replacement graft in the gap at immediately placed implants: a randomized clinical trial. Clin Oral Implants Res 28(8):902-910

13. E. Mellati, S. Chen, H. Davies, W. Fitzgerald, I. Darby, Healing of Bio-Oss $(\mathrm{R})$ grafted marginal gaps at implants placed into fresh extraction sockets of incisor teeth in dogs: a study on the effect of submerged vs. non-submerged healing, Clin Oral Implants Res 26(5) (2015) 553-62

14. Weigl P, Strangio A (2016) The impact of immediately placed and restored single-tooth implants on hard and soft tissues in the anterior maxilla. Eur J Oral Implantol 9(Suppl 1):S89-S106
15. Esposito M, Grusovin MG, Polyzos IP, Felice P, Worthington HV (2010) Timing of implant placement after tooth extraction: immediate, immediate-delayed or delayed implants? A Cochrane systematic review. Eur J Oral Implantol 3(3):189-205

16. Valentini P, Abensur D, Albertini JF, Rocchesani M (2010) Immediate provisionalization of single extraction-site implants in the esthetic zone: a clinical evaluation. Int J Periodontics Restorative Dent 30(1):41-51

17. R.E. Jung, A. Ioannidis, C.H.F. Hammerle, D.S. Thoma, Alveolar ridge preservation in the esthetic zone, Periodontol 2000 77(1) (2018) 165-175

18. R.C. Team, R: a language and environment for statistical computing. R Foundation for Statistical Computing, (2012)

19. Furhauser R, Mailath-Pokorny G, Haas R, Busenlechner D, Watzek G, Pommer B (2017) Immediate restoration of immediate implants in the esthetic zone of the maxilla via the copy-abutment technique: 5-year follow-up of Pink Esthetic Scores. Clin Implant Dent Relat Res 19(1):28-37

20. Souza AB, Alshihri A, Kammerer PW, Araujo MG, Gallucci GO (2018) Histological and micro-CT analysis of peri-implant soft and hard tissue healing on implants with different healing abutments configurations. Clin Oral Implants Res 29(10):1007-1015

21. Furhauser R, Florescu D, Benesch T, Haas R, Mailath G, Watzek G (2005) Evaluation of soft tissue around single-tooth implant crowns: the pink esthetic score. Clin Oral Implants Res 16(6): 639-644

22. L.S.J. Hedderich, Angewandte Statistik, Springer-Verlag2006

23. Faul F, Erdfelder E, Lang AG, Buchner A (2007) G*power 3: a flexible statistical power analysis program for the social, behavioral, and biomedical sciences. Behav Res Methods 39(2):175-191

24. Chen ST, Buser D (2009) Clinical and esthetic outcomes of implants placed in postextraction sites. Int J Oral Maxillofac Implants 24(Suppl):186-217

25. Gehrke P, Lobert M, Dhom G (2008) Reproducibility of the pink esthetic score-rating soft tissue esthetics around single-implant restorations with regard to dental observer specialization. J Esthet Restor Dent 20(6):375-384 discussion 385

26. Hof M, Umar N, Budas N, Seemann R, Pommer B, Zechner W (2018) Evaluation of implant esthetics using eight objective indices-comparative analysis of reliability and validity. Clin Oral Implants Res

27. Cosyn J, Sabzevar MM, De Bruyn H (2012) Predictors of interproximal and midfacial recession following single implant treatment in the anterior maxilla: a multivariate analysis. J Clin Periodontol 39(9):895-903

28. Esposito M, Barausse C, Pistilli R, Jacotti M, Grandi G, Tuco L, Felice P (2015) Immediate loading of post-extractive versus delayed placed single implants in the anterior maxilla: outcome of a pragmatic multicenter randomised controlled trial 1-year after loading. Eur J Oral Implantol 8(4):347-358

29. Noelken R, Moergel M, Pausch T, Kunkel M, Wagner W (2018) Clinical and esthetic outcome with immediate insertion and provisionalization with or without connective tissue grafting in presence of mucogingival recessions: a retrospective analysis with follow-up between 1 and 8 years. Clin Implant Dent Relat Res 20(3):285-293

30. Zuiderveld EG, den Hartog L, Vissink A, Raghoebar GM, Meijer HJ (2014) Significance of buccopalatal implant position, biotype, platform switching, and pre-implant bone augmentation on the level of the midbuccal mucosa. Int J Prosthodont 27(5):477-479

31. Chen ST, Darby IB, Adams GG, Reynolds EC (2005) A prospective clinical study of bone augmentation techniques at immediate implants. Clin Oral Implants Res 16(2):176-184

32. Mello CC, Lemos CAA, Verri FR, Dos Santos DM, Goiato MC, Pellizzer EP (2017) Immediate implant placement into fresh extraction sockets versus delayed implants into healed sockets: a 
systematic review and meta-analysis. Int J Oral Maxillofac Surg 46(9):1162-1177

33. G. Cannizzaro, P. Felice, A. Trullenque-Eriksson, M. Lazzarini, E. Velasco-Ortega, M. Esposito, Immediate vs early loading of $6.6 \mathrm{~mm}$ flapless-placed single implants: 9 years after-loading report of a split-mouth randomised controlled trial, Eur J Oral Implantol 11(2) (2018) 163-173

34. Gallucci GO, Grutter L, Chuang SK, Belser UC (2011) Dimensional changes of peri-implant soft tissue over 2 years with single-implant crowns in the anterior maxilla. J Clin Periodontol 38(3):293-299

35. Rokn A, Bassir SH, Rasouli Ghahroudi AA, Kharazifard MJ, Manesheof R (2016) Long-term stability of soft tissue esthetic outcomes following conventional single implant treatment in the anterior maxilla: 10-12 year results. Open Dent J 10:602-609
36. Nowzari H, Chee W, Yi K, Pak M, Chung WH, Rich S (2006) Scalloped dental implants: a retrospective analysis of radiographic and clinical outcomes of 17 NobelPerfect implants in 6 patients. Clin Implant Dent Relat Res 8(1):1-10

37. Kan JY, Rungcharassaeng K, Liddelow G, Henry P, Goodacre CJ (2007) Periimplant tissue response following immediate provisional restoration of scalloped implants in the esthetic zone: a one-year pilot prospective multicenter study. J Prosthet Dent 97(6 Suppl): S109-S118

38. Noelken R, Morbach T, Kunkel M, Wagner W (2007) Immediate function with NobelPerfect implants in the anterior dental arch. Int J Periodontics Restorative Dent 27(3):277-285

Publisher's note Springer Nature remains neutral with regard to jurisdictional claims in published maps and institutional affiliations. 